\title{
XXXIII. On the character of the light radiations emitted by the vapours of magnesium, copper, and manganese under the selective actions of thermo-chemical and thermo-electrical excitations
}

\section{G.A. Hemsalech}

To cite this article: G.A. Hemsalech (1920) XXXIII. On the character of the light radiations emitted by the vapours of magnesium, copper, and manganese under the selective actions of thermo-chemical and thermo-electrical excitations, Philosophical Magazine Series 6, 40:237, 296-315, DOI: $10.1080 / 14786440908636127$

To link to this article: http://dx.doi.org/10.1080/14786440908636127

\section{Published online: 08 Apr 2009.}

Submit your article to this journal $₫$

\section{Џ Article views: 2}

Q View related articles 5

Citing articles: 1 View citing articles 주 
XXXIII. On the Character of the Light Radiations emitted by the Vupours of Magnesium, Copper, and Manganese under the Selective Actions of Thermo-chemical and Thermoelectrical Eacitations. By G. A. HeMsaLECH*

[Plates VIII. \& IX.]

$\S 1$. Introduction.

THE flow of a heavy current of electricity through a 1 plate of graphite is accompanied at high temperatures by the appearance of the red fringe. This phenomenon is caused by part of the heating current passing outside the plate as thermelectronic current through the strongly ionized vapours in the protected space. The spectroscopic effect produced by the thermelectronic current is quite distinct from that caused by the action of the plate temperature upon the chemical compounds which form the luminous vapour $t$. In fact the difference between these two effects is as striking as that which has been noted between the spectra emitted by the explosion region and the outer mantle of the air-coal gas flame. For the special case of iron vapour the results of my experiments leave no room for doubt that the character of the spectrum emitted by the luminous vapour in the protected space is identical with that observed in the onter mantles of flames. With regard to the more complex spectrum observed in the explosion region of the air-coal gas flame, I have attributed its origin to the decomposition or breaking up of the iron compound, owing to the existence of a strong chemical affinity between the iron atom and nitrogen $f$. In like manner I have ascribed the origin of the fringe emission to the electrolytic decomposition of metal compounds by the thermelectronic current. We should, therefore, in accordance with these views, expect to observe some similarity between the spectra caused by chemical excitation in the Bunsen cone and those emitted under thermo-electrical excitation in the fringe, since each of these processes is supposed to involve the breaking un of a compound molecule. Thus we should anticipate that the characteristic cone lines (class III.) of iron, cobalt, nickel, \&c. will be sensitive to the thermelectronic current and form part of the fringe emission, whereas at the same time the flame lines (classes I. and II.) of these elements would be observed in the luminous vapour beneath the fringe.

* Communicated by the Author.

+ Hemsalech, Phil. Mag. ser. 6, vol. xxxix. p. 241 (1920).

$\ddagger$ Hemsalech, Phil. Mag. ser. 6, vol. xxxiv. p. 229 (1917). 
In order to verify the results of these considerations experimentally, it is necessary to fill the protected space with the vapour of the metal to be examined. This was accomplished by means of a very simple method based upon the observed fact that the vapours of any substance placed on the upper surface of the incandescent graphite plate pass automatically into the protected space beneath. In this way it has been possible to examine the spectra of a great many substances and study the relative effects of thermo-chemical and thermoelectrical excitations upon their bands and lines. The results of this investigation have clso completely confirmed my anticipations with regard to the similarity between the characteristic emissions caused respectively by chemical and thermo-electrical excitations.

The present paper deals briefly with the observations and experiments which have led to the establishment of the new method, and with the application of the latter to the spectra of magnesium, copper, and manganese.

\section{\$2. Observation of fringe emission with an umprotected plate of graphite.}

The experiments described in an earlier paper were made with graphite plates protected from excessive loss of heat through radiation by means of a cover of carborundum powder. Under these conditions the temperature of the under surface was found to be from $200^{\circ}$ to $300^{\circ} \mathrm{C}$. higher than when the plate was unprotected. Further, the carborundum powder employed contained many impurities, notably $\mathrm{Ca}, \mathrm{A}], \mathrm{K}, \mathrm{Na}, \mathrm{Sr}, \mathrm{Mn}, \mathrm{Fe}$, \&c., and the protected space beneath the plate became filled with a great variety of highly ionized vapours in addition to those expelled by the graphite. The presence of these vapours was, however, found to be of great advantrge, because it provided the opportunity of comparing the spectra of these elements with those emitted by them in the tube-furnace. The carbon tubes employed in my furnace work contained as impurities nearly all the same elements as the carborundum powder, and this fact proved to be invaluable for establishing the identity of the character of the emissions given by these substances in the carbon tube-furnace and in the luminous vapour beneath an electrically heated plate of graphite. But for the detailed investigation of the spectrum of some definite metal or other substance, it is of course essential to reduce the disturbing influence of the presence of impurities to a minimum. For this reason it is preferable to dispense

Phil. Mag. S. 6. Vol. 40. No. 237. Sept.1920. X 
with the carborundum altogether whenever possible; the loss of heat entailed thereby is compensated for by increasing the intensity of the heating current-an operation which involves the raising of the value of the potential gradient along the plate. It has not been possible to prepare a new set of temperature determinations for the unprotected plate, but it will be perfectly permissible for the purpose of the present investigation to assume a reduction of about $250^{\circ} \mathrm{C}$. at the highest temperatures as compared with the protected plate. The dimensions of the graphite plates used in these experiments and the method of mounting them were the same as those already given in a preceding paper. A fresh plate was used for every observation.

It will be remembered that with a heating current of about 205 amperes the under surface of the protected plate gave a temperature of about $2700^{\circ} \mathrm{C}$., and in its vicinity was seen the carbon band $\lambda 3883$. Now, with a heating current of the same intensity passing through an unprotected plate no sin $\mathbf{n}$ of this band is observed beneath the plate, but a trace of it is found in the immediate vicinity of the upper surface. When the intensity of the heating current is raised to about 250 amperes, the red fringe emission is well developed on both sides of the plate; in fact, the upper fringe passes to a greater distance from the surface than the lower one. In like manner the lines and bands of the luminous vapour which originates from the impurities expelled by the graphite (principally $\mathrm{Ca}, \mathrm{Sr}, \mathrm{Li}, \mathrm{Na}, \mathrm{Fe}$ ) pass to a greater distance above the plate than below. This is of course caused by the convexion currents which rise up from the plate and carry these vapours through a certain distance before their luminous vibrations have ceased. About half of the total amount of luminous vapour which appears above the plate emanates from the under surface, whence it passes first into the protected space and then upwards round the edges. This latter fact may possibly explain the greater extension of the upper fringe; for these strongly ionized vapours coming direct from the protected space would by virtue of their upward drift enable the thermelectronic current to spread over a greater vertical distance near the edge of the plate. This explanation for the greater extension of the upper fringe emission receives support by the observation that, when appreciable amounts (as indicated by the degree of development of the spectrum) of iron vapour are expelled from the graphite, the fringe emission always passes to a greater distance from the plate, as though vapour of this metal possessed a relatively high degree of conductivity for the thermelectronic current. In this connexion it is well to 
of Magnesium, Copper, and Manganese.

state that graphite plates vary considerably with regard to the nature and quantity of impuritios contained. Thus it often happens that of two plates, although cut from the same stratum, one will be quite free from iron, whereas the other will show a highly developed spectrum of this element. It is therefore essential, when comparing photographs of fringe emissions as given by different plates, to choose only such records as spectroscopically contain similar amounts of impurities.

What complications may arise through the presence of certain impurities is further illustrated by the fact that in their absence the fringe emission is but slightly affected by external magnetic fields. Thus, in the case of graphite plates free from spectroscopic traces of iron, but containing small amounts of $\mathrm{Ca}, \mathrm{Sr}$, and $\mathrm{Ba}$, a magnetic field of from 1500 to 2000 C.G.S. units is required in order to appreciably displace the fringe emission. Much greater displacements are obtained in the presence of large amounts of iron vapour, derired from boiling iron metal on the top of the plate. The results of these new obscrvations help to explain the relatively great displacements which I obtained for the fringe emission with feeble magnetic fields. The considerable amount of luminous vapours driven out by the carborundum and passing through the protected space beneath the plate formed a highly conducting medium through which the thermelectronic current was able to diffuse. Further, the swarms of electrified particles resulting probably from the breaking up of a potassium compound, and the true nature of which had then not yet been recognized, were largely instrumental in bringing about the drawn-out appearance of the red fringe emission. The positively charged particles are especially affected by magnetic forces, and on being drawn away from the plate the space through which they pass becomes strongly ionized. On this view the great displacements of the firinge emission would be caused by the diffusion downwards of the thermelectronic current, which, helped by the external magnetic field, would tend to follow the track of the electrified particles.

As a result of this new development of the subject, the explanation which I have given respecting the sharp outline of the red fringe and its spectrum emission becomes untenable, except perhaps in the case when free electrified particles are present; for in view of the small effect which magnetic forces have upon the fringe emission when only small amounts of ionized vapour are present, such as in the case with the unprotected plate, it seems hardly possible that the relatively feeble magnetic field due to the heating $\mathrm{X} 2$ 


\section{Mr. G. A, Hemsalech on the Luminous Vapours}

current could have any influence in shaping the outline of the fringe. I am at present unable to offer a satisfactory explanation for this peculiarity of the red fringe emission, but wish to call attention to the fact that most luminous phenomena which owe their origin to the flow of an electric current at atmospheric pressure present a sharp outline, which they retain even when acted upon by magnetic forces or, mechanically, by air-currents. Thus the initial discharge which marks the path of the condenser current in a capacity spark passing between metal poles is a sharply-defined luminous band stretching across the space between the electrodes*. (The more diffused aureole which envelops the initial discharge is formed by luminous vapour of the metal, or more probably its compounds with oxygen and nitrogen. This part of the phenomenon develops at a later stage than the initial discharge and does not convey the electric current.) Again, the pilot spark and the luminous ares formed when the oscillations in a self-induction spark are separated by means of an air-blast are all sharply defined $\dagger$. But even when a strong magnetic field is acting upon a high-tension discharge, the drawn-out luminous figure thus produced presents a very sharp contour line along its outer edge $+;$ and, as I shall show in a subsequent communication, the path figures described by electrified potassium particles under the influence of magnetic forces are all characterized by their well-defined outlines. 'Thus it would seem that the sharp borders of these phenomena cannot be caused by the magnetic fields set up by the electric current; there must be some other force which tends to keep the individual constituents of a stream of electrons or ions confined within certain definite bounds. But whatever the true explanation may be, the sharply-defined boundary surface of the red fringe is quite in keeping with the characteristic features of a luminous phenomenon, the origin of which can be traced back to the flow of an electric current.

Plate VIIT. represents the red end of the fringe spectrum as obtained with an unprotected plate of graphite containing an unusual amount of calcium as impurity. The actual vertical distance to which the fringe and the luminous vapour rise may be ganged by comparison with the edge of the plate, which is $0.95 \mathrm{~mm}$. across. The bright individual band $\lambda 626$ which rises high above the plate coincides with

* Schuster and Hemsalech, Philos. Trans. Royal Society, vol. 193, pp. 189-213 (1899).

+ Hemsalech, Comptes Rendus de l'Aeadémie des Sciences, t. 111 p. $1108(1005)$.

I Hemsalech, ibid. t. 152. p. 1086 (1911). 
a similar band given by calcium in the outer mantles of flames; the emission of this band is controlled by the temperature of the plate. The lower red fringe extends only to a very short distance from the plate; but the upper fringe, thanks to the upward rush of relatively great quantities of calcium vapour, attains about four times that distance. Particular attention should be directed to the abrupt extinction of the upper fringe bands in spite of the upward motion of the vapours. This, as has already been explained, is of course quite in accordance with the electrical origin of the fringe; for were the emission of these bands solely controlled by the plate temperature, they would, like the great flame band, rise higher and die out only gradually.

\section{§3. Circulation of the luminous vapour round the plate of graphite.}

It was suggested in $\$ 4$ of my preceding paper that the bluish vapour observed beneath a plite of graphite covered with carborundum powder is caused by the cooling of the luminous vapour at the boundary surface of the protected space. When no carborundum or other substance is placed on the graphite plate the bluish vapour is not observed; hence, in the former case the vapours which filled the protected space must have in some way passed from the upper surface of the graphite plate into the space below. Numerous experiments were made in order to account for this fact, and the following obsurvations seem to throw some light on the

Fig. 1.

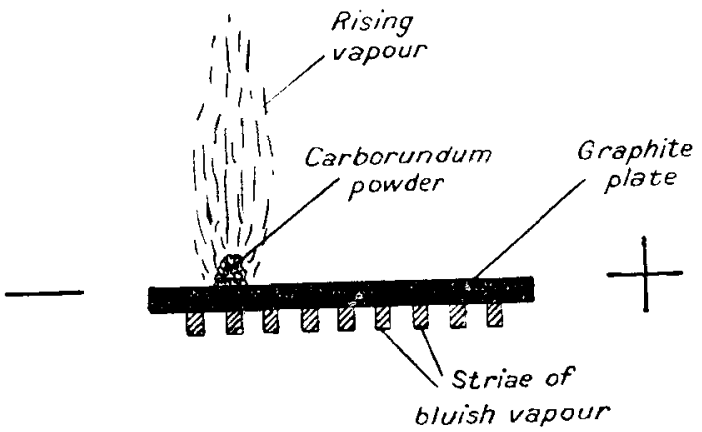

Striated appearance of bluish vapour.

manner in which the displacement of the metal vapour is accomplished. A small quantity of impure carborundum powder was laid upon the negative end of the graphite plate as shown in fig. 1. When the temperature of the latter was 
raised to the necessary degree, there appeared in the place generally occupied by the continuous band of bluish vapour a long series of approximately equidistant bluish patches or striæ. No vapour was seen above the plate except that which rose vertically upwards from the small heap of carborundum. An upwards acting external magnetic field had apparently no effect upon the striation. When the small heap of carborundum was placed near the positive end of the plate the bluish striæ were observed only just beneath that end, and did not extend towards the opposite one. A contrary effect was observed with calcium carbide. A small quantity of this material placed upon the negative end produced only a short horizontal streak of bluish vapour beneath that end. When, however, a little calcium carbide was put near the positive end, flocculi of light grey vapour formed beneath, and appeared to move towards the negative end like a succession of closely-placed smoke puffs. When larger quantities of carborundum are placed upon the plate the individual striæ are merged into a continuous bluish band. Thus, when only a small heap of the substance is used the vapour proceeding from it follows a narrow track, the width of which is about equal to that of a stria. There can be little doubt that the bluish strix are formed in a similar manner as the bluish vapour-namely, by the cooling of luminous vapour at the boundary surface of the protected space.

Further, the orderly arrangement of the striæ seems to. indicate that the encounters with cool air as the luminous vapour moves towards the positive end of the graphite platetake place at regular intervals. This fact suggests that the particles concerned execute some uniform periodic motion, such as might result if the path of the luminous vapour proceeding from the small heap of carborundum formed a helix round the plate. A path of this kind could be conceived to be caused by the combined actions of the electric and the magnetic fields set up by the heating current. Let. us consider the case of a negatively charged particle, such as might originate from the electrolytic decomposition of a compound molecule by the thermelectronic current in the upper fringe, moving along the top surface towards the positive end of the plate. In doing so the particle crosses lines of magnetic force, and is deviated in the direction of the magnetic south. Since the lines of magnetic force form closed oblongs round the plate, the particle in moving towards the south will tend to describe a similar figure; but as it also moves under the action of the electric field in a 
direction normal to the plane of this oblong, its path is not a closed one, but forms a flattened helix between the negative and positive ends of the graphite plate. If, instead of a single particle, there be an uninterrupted and abundant supply of them, such as would most likely be furnished by tha thermelectronic current from the small heap of carborundum, the stream of particles would probably form a layer of appreciable depth; and their combined system of paths, each of which forms a helix, would wind itself round the graphite plate like a screw-thread. This path system would probably be confined to the region of the red fringe, for as soon as a particle has passed out of the latter, it will recombine to form a neutral molecule of luminous vapour. In those places where the helix passes near the border of the protected space or actually out of it, the electrified particles travelling along it will come into contact with relatively cool air and form a stria of bluish vapour. Evidently there will be as many striæ as there are turns in the helix. Hence, on this view, the ions as they move in the direction of the electric field are whirled round the plate of graphite by the magnetic field due to the heating current, and the bluish striæ represent those portions of a helical path which cross the boundary surface of the protected space.

\section{\$4. Possible causes of the formation and downward drift of the luminous vapour in the protected space.}

It bas been shown that the emission centres of the luminous vapour travel down to a considerable distance from the electrically heated plate of graphite, even when a strong magnetic force is acting upwards ; in fact, they behave in this respect like nentral molecules. 'Their presence far down in the protected space cannot, therefore, be attributed solely to the action of the magnetic field established round the plate by the heating current. Without for the present attempting to find a definite solution of the problem, it may be useful, however, to call attention to one or two possible explanations. Thus the luminous vapour might originate from the recombination of metal and carbon atoms near the outer edges of the helical path, especially in those places where the force of affinity between the atoms is great enough to counteract the decomposing action of the thermelectronic current. If large quantities of ions pass through the fringe, it is conceivable that many of them will be pushed out of the fringe owing to overcrowding. Once out of the sphere of action of the thermelectronic current they will immediately reassociate to form neutral molecules, and their 
304 Mr. G. A. Hemsalech on the Luminous Vapours

downward drift would simply be cansed mechanically by the continual expulsion of fresh ions from above. But against this explanation stands the fact that even with very small quantities of luminous vapours, such as are obtained with an unprotected plate of graphite, the emission centres still drift away from the plate downwards against strong magnetic forces. Since there can be no question in this case of a mechanical push due to overcrowding of the space, it seems to me that the only forces which can act upon the molecules of the luminous vapour are gravity and radiation pressure. In any theory concerning the downward drift of the emission centres in the protected space of a single plate resistance furnace the possible action of either of these two forces or of both will undoubtedly deserve serious consideration.

\section{§. Practical application of the foregoing observations to the spectroscopic analysis of metal vapours.}

The fact that metal vapours originating from substances laid upon the top surface of the electrically heated plate of graphite pass automatically into the protected space beneath, at once provides a most convenient method of stridying the spectroscopic or other properties which characterize these vapours at high temperatures. The experimental arrangements employed for this purpose may, on account of the rôle played by the graphite plate, be regarded as a single plate resistance-furnace, and will be referred to as such hereafter. Exhaustive trials have shown that practically any substance may be examined under these conditions by placing small quantities of it upon the plate, preferably in two places, nne on either side of the slit image as indicated in fig. 2. The two portions of the substance should be not

Fig. 2.

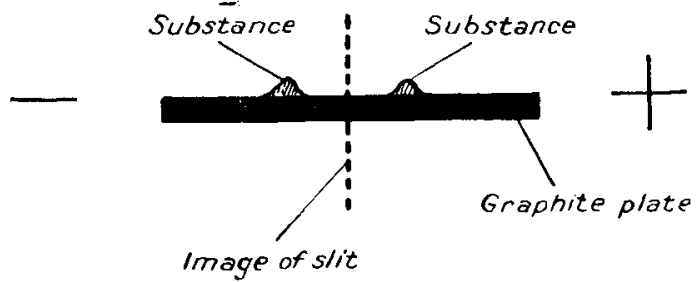

Method of observing spectrum of a substance with single plate resistance-furnace.

less than $10 \mathrm{~mm}$. apart, in order to prevent the formation of a conducting deposit on the graphite surface between them. 
If the substance be a metal which ensily forms a carbide, such as $\mathrm{Ca}, \mathrm{Fe}, \mathrm{Co}, \mathrm{Ni}, \mathrm{cc}$, and therefore adheres to the surface of the graphite plate, no covering with carborundum powder is required. In the case of a volatile metal, mineral, or rock, \&c., it is often ol advintage to first crush or in some other way subdivide the material, and place small quantities of it all over the plate, which is then covered with a $\frac{3}{8}$ in. thick layer of pure carborundium No. 80. But whenever possible the protecting layer should be dispensed with, as it always introduces lines and bands due to impurities contained in the carborundum. Such metals as copper and silver, which do not adhere to the gruphite, may be prevented from rolling off the plate-they are of spheroidal shape in the molten state-by placing small pieces of graphite round them. Particular methods employed for the purpose of mounting and holding substances will be given in each case.

With the arrangement sketched in fig. 2 the spectrum of the vapours given off by the substance is of course observed both below and above the plate. But since the greater quantity of vapour is immediately carried upwards by convection, only a relatively small amount of it passes into the protected space. It is no doubt for this reason that the spectrum emission due to thermo-chemical excitation is brighter and passes to a much grenter distance from the plate in the region above than in the protected space below. Also the emission due to thermo-electrical excitation, although in many cases appreciably feebler above the plate than below, pisses to a greater height, probably owing to the upward rush round the edge of highly ionized vapours from below. For these reasons it is preferable to make all observations in the protected space beneath the plate, where, thanks to the more tranquil state of the vapours and the absence of convection currents, the two emissions are more sharply differentiated than above. Only doubtful cases with regard to lines caused by thermo-chemical excitation are for the sake of confirmation examined in the uprising vapour above the plate.

As usual an image of the incandescent plate and protected space below it is sbarply focussed upon the slit of a spectrograph in such a way that the slit bisects the plate as marked in fig. 2. The resulting spectrum shows a continuous bright band caused by the edge of the incandescent graphite plate and, immediately below it, a sharplydefined region of short lines and bands which constitute the fringe emission (thermo-electrical excitation). Superposed 
upon the latter, and passing much farther from the plate, is the spectrum caused by the action of heat upon chemical compounds of the elements contained in the substance under examination (thermo-chemical excitation). The character of a light radiation can then be derived from the relative degree of its response to these two modes of excitation as indicater by the corresponding line intensities in the fring $\theta$ and in the luminous vapour.

In order to ficilitate the grouping of the lines according to character, the following three standard types based upon their relative appearance in fringe and luminous vapour have been adopted :-

First type. Cong lines. These constitute the so-called flame lines, which are emitted by the mantles of the various low- and high-temperature flames. They are culused by the action of heat upon chemical compounds, and their intensities are controlled by the plate temperature. The thermelectronic current does not appear to affect these lines appreciably, and they generally pass far down from the under surface of the plate through the protected spnce, fading away gradually.

Second type. Tadpole lines. These are specially sensitive to the thermelectronic current in the fringe and to a lesser degree also to thermo-chemical actions in the luminous vapour. On account of this peculiarity these lines appear to consist of an intense head, to which is attached a long thin tail. They are strongly emitted in the explosion region of the air-coal gas flame, but are either absent from, or appear only as mere traces in the hottest zone of this flame just above the cone. They are generally brought out in the mantles of hightemperature flames.

Third type. Short lines. The emission of these lines is almost entirely confined to the fringe; only faint traces are in some cases observed under thermo-chemical excitation at very high temperatures. They are, however, easily emitted under chemical excitation in the explosion region of the air-coal gas flame.

This classification naturally only serves as a guide in the establisbment of the most probable character of a line, as in some cases it is difficult to decide into which category a line should be placed. For this reason the relative intensity of each line has been recorded both for the fringe and the region just beneath it. 


\section{§6. Magnesium.}

The substances examined were metallic magnesium, its chloride, sulphate, and oxide. In the case of the first three of these substances a protecting layer of pure carborundum No. 80 was employed. The oxide, on the other hand, was laid upon the plate as shown in fig. 2, without a covering. In order to prevent the lumps of oxide from moving when in the liquid state three small pieces of graphite were placed round each. The general character of the line spectrum is independent of the nature of the compound used, but on account of the high melting-point of the oxide and the fact that it can be used without a carborundum covering, this substance gives a brighter and better-developed spectrum than the more volatilo materials. The relative intensities given in the following table are founded upon a photographic record obtained in this way with magnesium oxide.

\begin{tabular}{|c|c|c|c|c|c|c|}
\hline \multirow[b]{2}{*}{$\lambda$. } & \multicolumn{3}{|c|}{ Single plate furnace. } & \multicolumn{2}{|c|}{ Air-coal gas flame. } & \multirow[b]{2}{*}{$\begin{array}{c}\text { Capacity } \\
\text { Spark } \\
\text { (electrical } \\
\text { excitation). }\end{array}$} \\
\hline & $\begin{array}{c}\text { Fringe } \\
\text { (thermo- } \\
\text { electrical } \\
\text { excitation). }\end{array}$ & $\begin{array}{c}\text { Luminous } \\
\text { Vapour } \\
\text { (therino- } \\
\text { chemical } \\
\text { excitation } \\
\text { at } 2900^{\circ} \text { O.). }\end{array}$ & Type. & $\begin{array}{c}\text { Cone } \\
\text { (chemical } \\
\text { excitation). }\end{array}$ & $\begin{array}{c}\text { Mantle } \\
\text { (thermo- } \\
\text { chemical } \\
\text { excitation } \\
\text { at } 1850^{\circ} \mathrm{C} \text {.). }\end{array}$ & \\
\hline $829 \cdot 35$ & 6 & 000 & tadpole & 10 & - & 50 \\
\hline 0.07 & 8 & 00 & & & - & 50 \\
\hline $338 \cdot 29$ & 10 & 0 & & 20 & - & 100 \\
\hline $571 \cdot 10$ & $\frac{1}{2}$ & $\frac{1}{2}$ & long & 5 & 5 & 3 \\
\hline $167 \cdot 32$ & 6 & $\frac{2}{2}$ & tadpole & 7 & - & 12 \\
\hline $2 \cdot 68$ & 8 & $l_{1}^{2}$ & , & 8 & - & 15 \\
\hline $5183 \cdot 60$ & 10 & 2 & , & 10 & - & 20 \\
\hline
\end{tabular}

The acting electric field in the vicinity of the plate was about $8 \frac{\text { volts }}{\mathrm{cm} .}$ and the plate temperature, allowing for the absence of a carborundum cover, about $3000^{\circ} \mathrm{C}$. The relative intensities under the heading "fringe" refer to that part of the vapour which radiates under the influence of the thermelectronic current, whereas those given under "luminous vapour" are controlled by the temperature prevailing just beneath the fringe, which bas been assumed to be about $100^{\circ} \mathrm{C}$. less than that of the plate. The scale of intensities is the same as that previously adopted *. Wavelengths are given in international units. In order to emphasize the significance of the results obtained with the single plate resistance-furnace the relative intensities of the

* Hemsalech, Phil. Mag. vol, xxxiii. p. 9 (1917). 
lines as observed by Dr. de Watteville in the cone and mantle of the air-coal gas flame ${ }^{*}$, and by me in the capacity spark + , have been added for comparison.

In addition to the line spectrum there also appeared certain bands, especially the one with head line at 5007.3. The bands are not affected in the fringe, but pass well down from the plate into the protected space and, like the flame line 4571 , die out gradually.

The tabulated results bring to light a most important fact-namely, the triplet lines, which are strongly emitted under thermo-electrical excitation, are precisely those which are likewise strongly emitted under chemical excitation in the explosion region of the air-coal gas flame and under electrical excitation in a capacity spark. Again, the only line which from its character as a long line is evidently a temperature line is also the only one which is emitted by the mantle of the air-coal gas flame. In the capacity spark it is a relatively feeble line, and appears, if at all, to be but slightly affected by electric actions. The fact that the triplets at 3838 and 518 , althongh very intense in the cone of the air-coal gas flame, do not show in the mantle just above the cone is probably due to the temperature of this flame-namely $1850^{\circ} \mathrm{C}$., being too low for their emission under thermo-chemical excitation. Even with the high temperature of the furnace they only come out as relatively faint lines below the fringe. There is no doubt that they will show in the oxy-acetylene flame, but no data are as yet available on this point. I have obtained them by simply burning a lump of magnesium metal in air, although in this case it is not quite certain whether and in how far the emission of these lines is controlled by the heat generated through combustion or by the chemical actions involved.

That the triplet lines of magnesium are particularly sensitive to electric actions will be further exemplified in a subsequent communication by the fact that with a two-plate furnace, in which a uniform electric field is established between two parallel plates, these lines always appear first at the cathode plate.

No trace of the spark line 4481, or of any line of the nebulous series, has been observed in the fringe or bluish vapour.

Pl. IX. $a$ shows the ultra-violet triplet of magnesium in the fringe; the long thin tails of these lines which represent those portions of the emission due to thermo-chemical

* De Watteville, 'Thèses de Doctorat,' Paris, p. 34 (1904).

† Hemsalech, 'Thèses de Doctorat, Paris, p. 92 (1901). 
excitation, do not show in the reproduction on account of their great feebleness. It will, however, suffice to point out the sudden cessation of the electrically controlled emission at the lower border of the fringe, which, like that of the $\mathrm{C}$ bands and $\mathrm{Ti}$ lines, is in striking contrast to the more gradual fading away of the lines of $\mathrm{Fe}$ and $\mathrm{Ca}$ under the control of the plate temperature. As compared with the other two spectra $b$ and $c$ on Pl. IX., the fringe emission of maynesium extends to a relatively greater distance from the graphite plate. This is probably due to the presence of iron vapour, which, as already explained in $\$ 2$, seems to be a particnlarly good conductor of the thermelectronic current at high temperatures.

\section{$\$ 7$. Copper.}

The metal as well as its oxide and chloride were employed both with and without a protecting layer of carborundum. The best results were, however, obtained with pieces of metallic copper oñ an unprotected plate of graphite. Since the metal boils already at about $2300^{\circ} \mathrm{C}$. it became necessary, in order to prevent the boiling mass from being thrown off the plate, to adopt special precautions, and the following method was found to work satisfactorily. The pieces of metal, instead of being placed near the middle of the plate as sketched in fig. 2, were brought close up to the end faces of the clamping bars as shown in plan view, fig. 3 . The

Fig. 3.

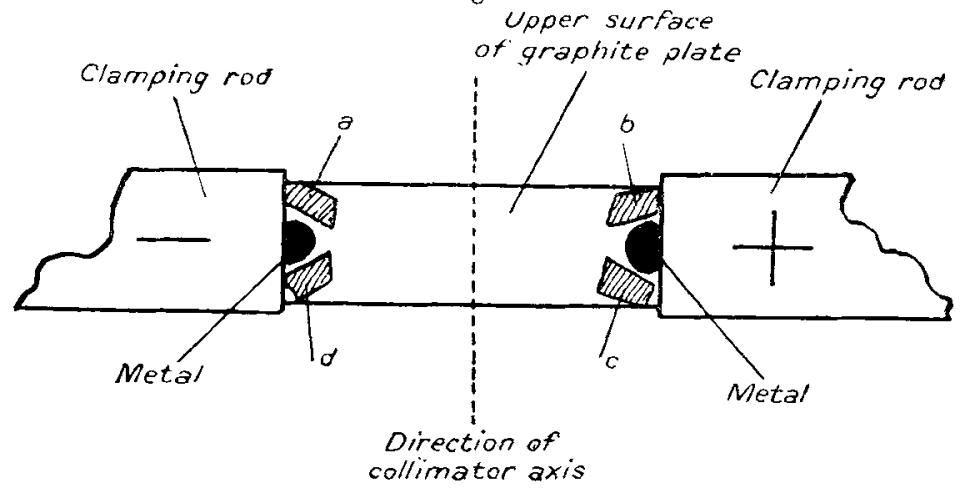

Nethod of obtaining spectrum of a metal having low boiling-point.

temperature here is considerably lower than near the middle of the plate, and the metal does not boil too violently. The lumps of copper were held in position by small pieces of 


\section{$310 \mathrm{Mr} . \mathrm{G}$. A. Hemsalech on the Luminous Vapours}

graphite $a, b, c, d$, care being taken to leave open a free passage towards the opposite end so as to enable the ionized vapours to creep along the surface of the plate under the impulse of the electric field due to the heating current. As before, the hottest part of the plate-namely, the middle, was focussed upon the collimator slit. Observations were made of the vapour on both sides of the plate.

The spectrum given by copper vapour under these conditions is composed of lines and bands; the latter are particularly well developed above the plate, and are probably due to oxidation of the metal, which is facilitated by the inrush of fresh air through convection. The band spectrum is practically identical with that observed for the same metal in the tube-furnace. With regard to the line spectrum the so-called flame lines are more intense above the plate than in the protected space beneath, but the electrically controlled lines have the same strength in the lower and upper red fringe, although in the latter they pass to a greater distance from the incandescent plate for reasons already explained in $\S 2$.

The tabulated results refer to the emission of copper vapour in the protected space beneath the plate, and are founded upon a photographic record obtained in the manner described at a plate temperature of about $2900^{\circ} \mathrm{C}$. The value of the acting electric field in the vicinity of the plate was $7.5 \frac{\mathrm{volts}}{\mathrm{cms} .}$. The relative intensities of the copper lines in the air-coal gas flame, as observed by Dr. de Watteville *, and in the capacity spark as found by me $\dagger$ have been added for comparison.

\begin{tabular}{|c|c|c|c|c|c|c|}
\hline & \multicolumn{3}{|c|}{ Single plate furnace. } & \multicolumn{2}{|c|}{ Air-coal gas flame. } & \multirow[b]{2}{*}{$\begin{array}{c}\text { Capacity } \\
\text { Spark } \\
\text { (electrical } \\
\text { excitation) }\end{array}$} \\
\hline$\lambda$. & $\begin{array}{l}\text { Fringe } \\
\text { (thermo- } \\
\text { electrical } \\
\text { excitation). }\end{array}$ & $\begin{array}{l}\text { Tuminous } \\
\text { Vapour } \\
\text { (thermo- } \\
\text { chemical } \\
\text { excitation } \\
\text { at } 2800^{\circ} \text { C.). }\end{array}$ & Type. & $\begin{array}{c}\text { Cone } \\
\text { (chemical } \\
\text { excitation). }\end{array}$ & $\begin{array}{c}\text { Mantle } \\
\text { (thermo- } \\
\text { chemical } \\
\text { exeitation } \\
\text { at } 1850^{\circ} \mathrm{C} \text {.). }\end{array}$ & \\
\hline 05.58 & 6 & 6 & long & 10 & 10 & 8 \\
\hline $3 \cdot 26$ & 2 & - & short & 3 & - & 10 \\
\hline $18 \cdot 20$ & 3 & - & short & 5 & -- & 15 \\
\hline $00 \div 20$ & l & 1 & long & 3 & $?$ & 2 \\
\hline $5782 \cdot 16$ & 3 & 3 & long & 10 & 10 & 5 \\
\hline
\end{tabular}

Dr. de Watteville has also very kindly supplied me with copies of his original photographs of the flame spectrum of copper, which go to show that the two lines 5106 and 5782 are equally intense in cone and mantle. With regard to the

* De Watterille, Thèses, p. 31.

† Herasalech, Thèses, p. 107. 
line 5700 , the presence of continuous ground and bands which in the mantle are stronger than in the cone has not permitted to decide whether or not this line is emitted by the mantle; for even if the intensity of this line in the mantle were the same as in the cone, it would hardly be possible to detect it for the reason just stated.

No other line of this element has been observed in the fringe or luminous vapour down to about $\lambda 3800$.

When comparing the results given by the single plate furnace with those obtained for the mantle of the air-coal gas flame, allowance must be made for the considerable difference in temperature between the two cases; for whereas the temperature of the mantle is only about $1850^{\circ} \mathrm{C}$, that of the protected space near the fringe is probably in the neighbourhood of $2800^{\circ} \mathrm{C}$. This great difference may well account for the fact that the visibility of the line 5700 in the protected space is not impeded by continuous ground to the same extent as in the air-coal gas flame. According to my results with the plate furnace, this line belongs most probably to type I., and I do not doubt that if a little oxygen were added to the air-coal gas nixture the intensity of the continuous ground would diminish and the line show up plainly. With regard to the remaining lines, the furnace results corroborate entirely Dr. de Watteville's observations respecting their character.

If now we compare the furnace results with those given by a capacity spark in which the emission of lines is predominantly caused by electrical excitation, the striking fact is brought out that the two lines which are most strongly emitted in the latter-namely 5153 and 5218-are precisely those which in the furnace are excited solely by the thermelectronic current. They are likewise emitted under chemical excitation in the cone, but are absent from the mantle; and the fact that no trace of them has been observed in the luminous vapour beneath the fringe goes to indicate that their emission is not stimulated by thermochemical excitation up to a high temperature. Thus, also in the case of copper, the spectroscopic effects produced by chemical excitation in the air-coal gas cone and by thermoelectrical excitation in the red fringe are the same.

Pl. IX. $b$ represents the spectrum given by copper vapour in the protected space of the single plate furnace. Special attention is invited to the unmistakable contrast between the short lines in the fringe and the long lines in the luminous vapour, which fact so manifestly bears witness to the difference in origin between these two types of lines. 


\section{Mr. G. A. Hemsalech on the Luminous Vapours}

\section{\$. Manganese.}

Two pieces of the metal were laid upon the graphite plate as shown in fig. 2, and photographic observations made both with a protecting layer of pure carborundum and without. The tabulated results are based on an experiment made with an unprotected plate raised to a temperature of about $3000^{\circ} \mathrm{C}$; the acting electric field was about $8 \frac{\text { volts }}{\mathrm{cms} \text {. }}$ The relative intensities for the lines in the luminous vapour refer to the region situated just below the fringe, where the temperature will be slightly less than on the surface of the plate. No detailed results concerning the air-coal gas flame spectrum of this element are as yet available, but Dr. de Watteville very kindly placed at my disposal copies of his original photographs of this spectrum, from which I was able to derive the relative intensities of the manganese lines in cone and mantle. These results as well as the relative intensities in are and spark for the lines of the same element according to Messrs. Exner and Haschek have been added for comparison.

\begin{tabular}{|c|c|c|c|c|c|c|c|}
\hline \multirow[b]{2}{*}{$\lambda$. } & \multicolumn{3}{|c|}{ Single plate furnace. } & \multicolumn{2}{|c|}{ Air-coal gas flame. } & \multirow[b]{2}{*}{ Arc. } & \\
\hline & $\begin{array}{c}\text { Fringe } \\
\text { (thermo- } \\
\text { electrical } \\
\text { exeitation). }\end{array}$ & $\begin{array}{l}\text { Luminous } \\
\text { Vapour } \\
\text { (thermo- } \\
\text { themical } \\
\text { excitation } \\
\text { at } 2900^{\circ} \mathrm{C} \text {.). }\end{array}$ & Type. & $\begin{array}{c}\text { Cone } \\
\text { (chemical } \\
\text { excitation). }\end{array}$ & $\begin{array}{c}\text { Mantle } \\
\text { (thermo- } \\
\text { chemical } \\
\text { excitation } \\
\text { at, } 1856^{\circ} \mathrm{C} \text {.). }\end{array}$ & & Spark. \\
\hline 4018.09 & 2 & 1 & tadpole & 2 & $\rightarrow$ & 10 & 8 \\
\hline 4050 & $1 \overline{0}$ & 10 & long & 10 & 10 & 100 & 20 \\
\hline 4033.06 & 8 & 8 & , & 10 & 10 & 100 & 20 \\
\hline $4034 \cdot 48$ & 6 & 6 & & 8 & 8 & 50 & 10 \\
\hline $4035 \cdot 73$ & 1 & $\frac{1}{2}$ & tadpole & $?$ & ? & 6 & 8 \\
\hline $4041 \cdot 34$ & 3 & $\frac{3}{2}$ & long? & 4 & - & 20 & 10 \\
\hline $4048 \cdot 73$ & 1 & $\frac{3}{d}$ & ,? & 2 & - & 8 & 7 \\
\hline 4055.55 & 2 & .13 & tadpole & 3 & - & 4 & 8 \\
\hline 4058.92 & 1 & $\frac{1}{2}$ & , & 2 & - & 4 & 6 \\
\hline $4063 \cdot 55$ & 1 & $\frac{\overrightarrow{1}}{2}$ & $\mu$ & 1 & - & 5 & 6 \\
\hline $4070 \cdot 32$ & 0 & 00 & long? & 0 & - & 4 & 3 \\
\hline $4079^{\circ}\left\{\begin{array}{l}20 \\
43\end{array}\right.$ & 2 & 1 & tadpole & 3 & - & 3 & 5 \\
\hline 4082.92 & 1 & 0 & ," & 3 & & 4 & 6 \\
\hline 408362 & I & 0 & ", & 3 & 一 & 3 & 6 \\
\hline 4235.31 & 2 & 000 & & 2 & 1 - & 10 & 20 \\
\hline 4257.65 & 00 & - & short? & observatio & on impeded & 3 & 4 \\
\hline 4265.92 & 0 & -- & ? & by & bands & 3 & 5 \\
\hline 4754.05 & 4 & $\frac{1}{3}$ & tadpole & 8 & $1 \quad-$ & & \\
\hline $47+2 \cdot 38$ & 1 & 00 & , & 2 & - & & \\
\hline 4766.41 & $\frac{3}{4}$ & 1000 & $"$ & 2. & - & & \\
\hline $4783 \cdot 45$ & 4 & 1 & ", & 8 & - & & \\
\hline 4823.52 & 4 & 1 & $"$ & 8 & -- & & \\
\hline $5341 \cdot 07$ & 00 & 000 & long & ? & ? & & \\
\hline $5394 \cdot 68$ & 2 & $1 \frac{3}{4}$ & ," & 5 & 5 & & \\
\hline $5432 \cdot 55$ & 1 & $\frac{3}{4}$ & ": & 4 & 4 & & \\
\hline
\end{tabular}


The following facts may be derived from these results :All lines which in the air-coal gas flame are equally strong in cone and mantle, and therefore mark their character as temperature lines, are of the "long" type in the furnacethat is to say, their emission in the latter is, just as in the flaine, controlled by temperature. Again, all the lines of the "tadpole" type which in the furnaee are particularly affected by thermo-electrical excitation are in the coal-gas flame emitted solely by chemical excitation in the explosion region. The three apparent exceptions-namely 4041, 4049, and 4070-which have been classed as long lines in the furnace emission, are probably also of the tadpole type, as may be expected from their relative intensities in fringe and luminous vapour; they are perhaps a little more sensitive to temperature than most other lines of this type, and would therefore occupy a position intermediate between long lines and tadpole lines. Lastly, nearly all the tadpole lines are enhanced in the spark as compared with the are. Special interest is attached to the line 4235 , which is a prominent spark line. Thermo-electrical excitation in the fringe brings it out with intensity 2 , whereas under almost similar conditions of temperature just outside the fringe, thermo-chemical excitation hardly stimulates its emission. Naturally it is absent from the mantle of the air-coal gas flame, but it is well brought out in the cone. Thus we find also in the case of manganese a very close agreement between the emission caused by chemical excitation in the cone of the air-coal gas flame and that due to thermoelectrical excitation in the red fringe of a single plate furnace.

Pl. IX. $c$ shows the enhancement in the red fringe of the three blue lines of manganese.

\section{§9. Summary.}

1. With an electrically heated plate of graphite, which is not covered with a layer of carborundum, the red fringe appears on both sides. The upper fringe will often extend to a greater distance from the plate than the lower one. This is probably caused by the upward rush of conducting vapours which are expelled from the under surface and pass round the sides of the plate into the space above. $\$ 2$.

2. In spite of the rapid upward motion of conducting vapours above the plate, the border line of the upper fringe is sharply defined and its spectrum emission stops abruptly in marked contrast to that of the luminous vapour. $\$ 2$.

Phil. Mag. S. 6. Vol. 40. No. 237. Sept. 1920. Y 


\section{Mr. G. A. Hemsalech on the Luminous Vapours}

3. In the absence of sufficient quantities of ionized vapours, strong magnetic fields of from 1500 to 2000 c.G.s. units must be applied in order to appreciably displace the red fringe emission. Consequently, the conclusion arrived at in $\$ 8$ of my preceding paper-namely, that the sharp outline presented by the red fringe and its spectrum emission are caused by the magnetic field due to the beating currentbecomes untenable. Although no satisfactory alternative explanation of this peculiarity of the fringe is offered, it is pointed out that most luminous phenomena which owe their origin to the flow of an electric current at atmospheric pressure present a sharp outline. $\$ 2$.

4. It is shown that the vapours which fill the protected space are in great part derived from substances placed upon the plate. The formation of striæ at the boundary surface of the protected space is interpreted as indicating that the vapours pass round the plate in a helical path. It is further suggested that such a path might be caused by the combined actions of the electric and magnetic fields set up respectively along and around the plate by the heating current. $\$ 3$.

5. A short discussion concerning the probable cause of the downward drift of the luminous vapour in the protected space has led to the suggestion that it might be due either to gravity or radiation pressure, or possibly even to the combined action of both. $\$ 4$.

6. A convenient method has been developed of readily ascertaining the relative sensitiveness of a spectrum line to thermo-chemical and thermo-electrical excitation. According to this method the character of a line is revealed by its relative intensity in fringe and luminous vapour. For the purpose of facilitating the grouping of lines having similar character three distinct types, based on their shape and appearance, have been adapted as standards-namely, long lines, tadpole lines, and short lines. The experimental arrangement underlying this method may be appropriately called a single plate resistance-furnace. $\$ 5$.

7. An investigation of the spectrum lines emitted by the vapours of magnesium, copper, and manganese has brought out the fact that the line emissions due to thermo-electrical and to chemical excitation are both of the same typenamely, the lines most strongly affected by the thermelectronic current in the fringe are precisely those which are characteristic of the explosion region of the air-coal gas flame. Their sensitiveness to electrical stimulation is further illustrated by the fact that their emission is appreciably enhanced in a capacity spark. $\$ \$ 6,7$, and 8 .

8 . The characteristic flame lines of magnesium, copper, and 
manganese, which in the air-coal gas flame are emitred by the mantle above the cone, appear all as long lines in the single plate furnace. This fact confirms their status as temperature lines. $\$ \S 6,7$, and 8 .

\section{\$10. Concluding Remarks.}

The very definite grouping of the spectrum lines of metal vilpours according to character, as revealed by the selective actions of thermo-electrical and thermo-chemical excitation with the single plate resistance-furnace, makes it appear hopeful that the new method of spectroscopic analysis developed in the course of this investigation will be of some help in the search for related lines in the case of metals possessing complicated line spectra. Furthermore, the remarkable agreement which has been shown to exist between the spectroscopic effects produced by thermoelectrical and chemical excitations goes to mark out the single plate furnace as a valuable means of both checking and supplementing the results given by flames. In particular this type of furnace provides the possibility of singling out the characteristic line emission which accompanies the decomposition of a chemical compound under temperature conditions unattainable in flames. Thus at a very high temperature and with the aid of electric actions the plate furnace performs the same function as the air-coal gas flame at a comparatively low temperature with the help of chemical actions. In this respoct the red fringe may be regarded as the electrical analogue of the explosion region; in both, the line emission by metal vapours is connected with the breaking up of compound molecules, but the manner in which this is brought about is probably different in each. The resulting luminous effects, however, are evidently of the same order in both, as has been so clearly established by these experiments.

The fact that an electric cirrent or-what may be regarded as its equivalent-a drift of electrons travelling under the action of a relatively feeble electric field is capable of strongly exciting characteristic spectrum radiations in metal vapours, may have some important bearing on certain astrophysical problems. Thus it is conceivable that at the very high temperature prevailing in the lower strata of the chromosphere or in the reversing layer an electric field of only a very minute fraction of a volt per centimetre may suffice to stimulate spectroscopic effects comparable to those which the relatively much more intense electric fields of our laboratory furnaces produce at considerably lower temperatures.

Manchester, May 1920. 
HEMSALECH.

Red Bands of Calcium in Fringe and Luminous Vapour.

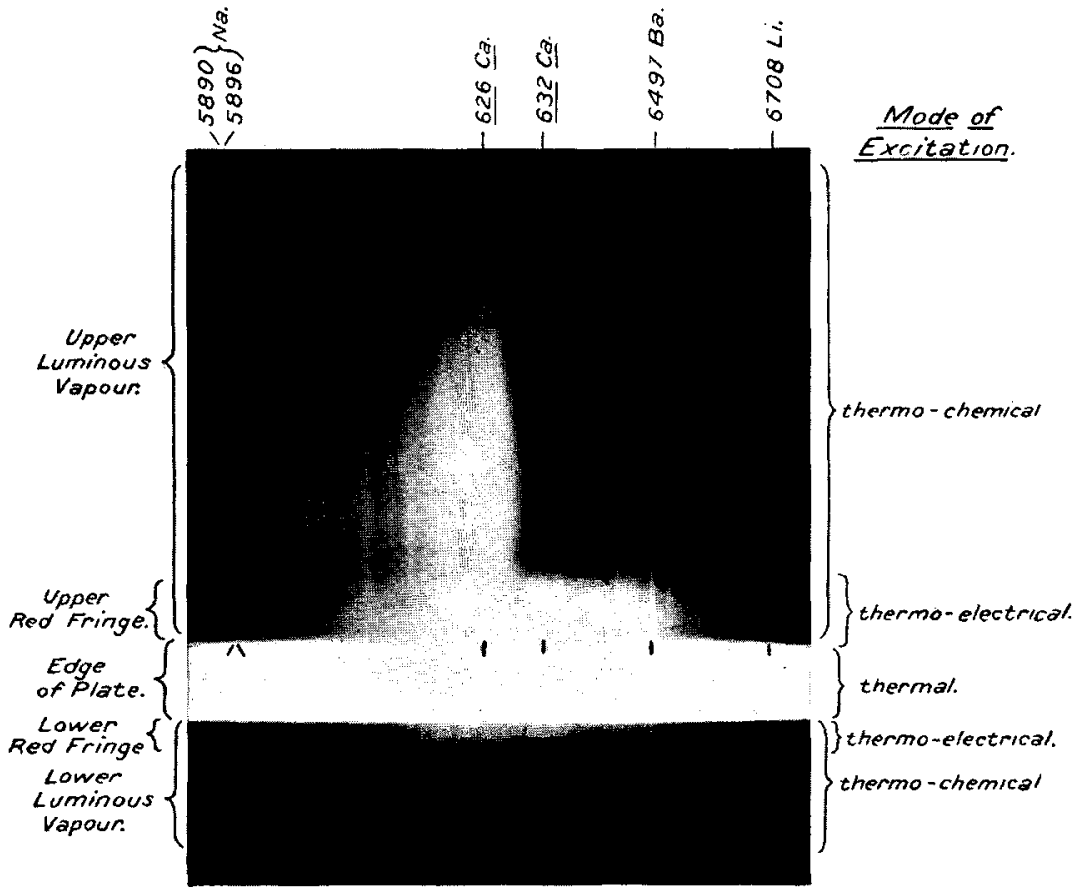

Plate temperature: about $3000^{\circ} \mathrm{C}$. Drop of Potential along plate: about $8 \frac{\text { volts }}{\mathrm{cm} .}$ 
HEMSALECH.

Phil. Mag. Ser. 6, Vol. 40, Pl. IX

Thermo-chemical and Thermo-electrical Excitation of Light Radiations in Metal Vapours.
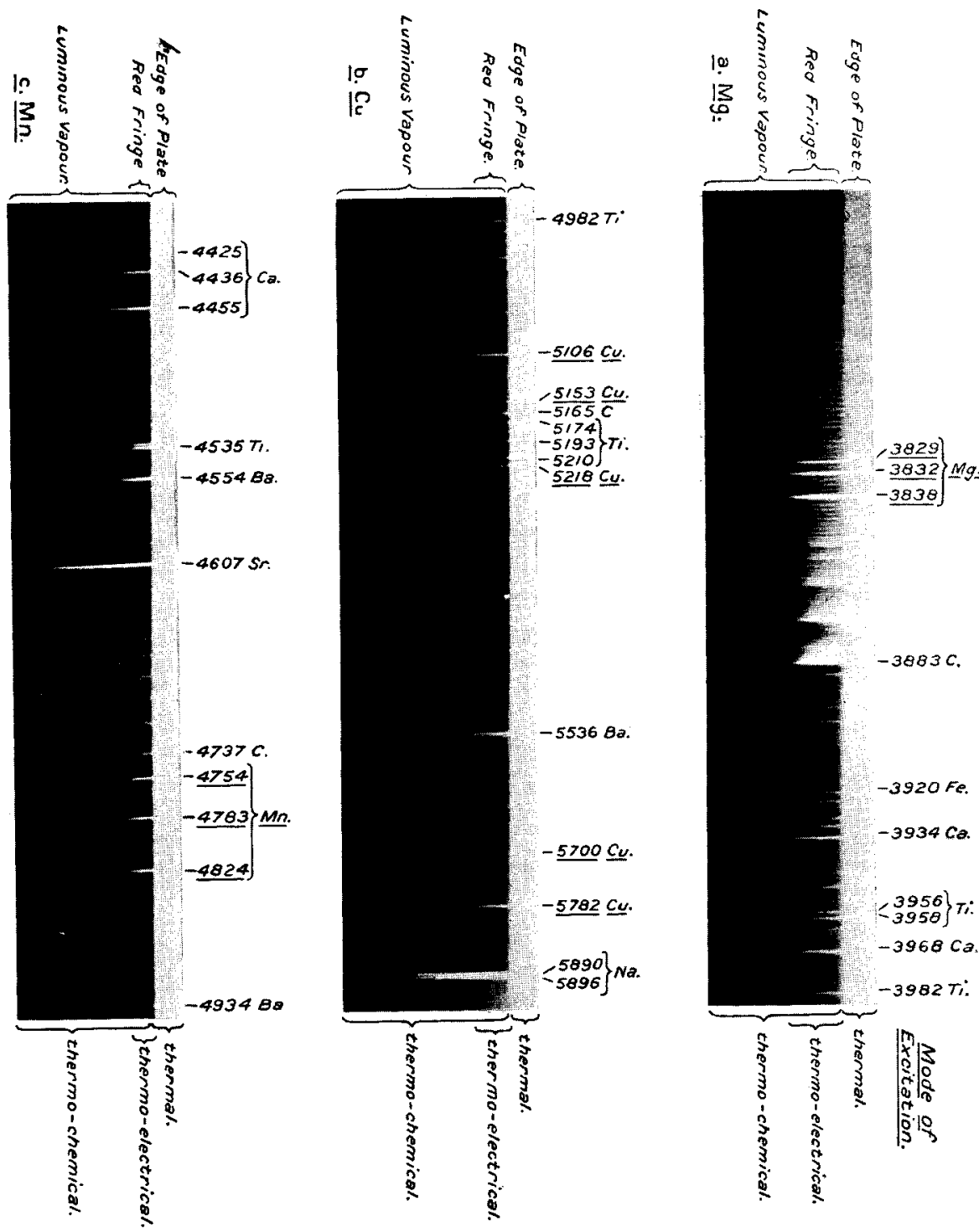

Plate temperature: about $3000^{\circ} \mathrm{C}$. Drop of Potential along plate: about $8 \frac{\text { rolts }}{\mathrm{cm} .}$ 